\title{
PROCEEDINGS OF THE AMERICAN CHEMICAL SOCIETY.
}

\author{
Regular Meeting May 4, 1883.
}

At Mr. Stebbins' request Prof. Leeds occupied the chair.

The minutes of the February meeting were read and approved.

The minutes of the meetings of the Board of Directors, held January 16, 1883, and March 20,1883, were also read.

The following papers were read :

1. On apparatus for producing high vacuum with low pressure, by C. J. Lawler.

2. Platinic Iodide as a test reagent for deleterious organic substances in potable waters, by Dr. A. R. Leeds.

3. A note by Dr. Breneman, on a "Eudiometer for Rapid Gas Analysis."

4. A note by Prof. A. R. Leeds, on "The Conversion of Carbon Monoxide to Dioxide by Active (i. e. Nascent) Oxygen."

The papers were followed by discussion participated in by Messrs. Stebbins, Casamajor, Alsberg and Iseeds, after which the Society adjourned.

Thomas S. Giaddixg,

Recording Secretary.

\section{NEW ASPIRATOR, CAPABLE OF GIVING A HIGH VACUUM WITH A LOW WATER PRESSURE:}

By C. J. LAwLER.

In the London Engineer for 1876, Mr. Bronson has described an aspirator, giving results which are about the same as those obtained with the apparatus which I propose to describe. The only merit claimed for the new aspirator is its greater simplicity.

With the new apparatus a vacuum equal to the barometer vacuum may be obtained, minus the tension of the water vapor corresponding to the temperature of the water used to work the apparatus.

This result can be reached with a water pressure not exceeding $5 \frac{1}{2}$ pounds.

The good results obtained with such very low water pressure, by means of an apparatus of very simple construction, have been 